\title{
Changing practice on confidentiality: further points for discussion
}

\author{
Derek F H Pheby Senior Registrar in Community Medicine, Bath District Health Authority
}

\section{Editor's note}

In the March 1982 issue of the Fournal Dr Pheby, a community health doctor, was one of several writers to discuss medical confidentiality. Dr Pheby urged doctors to minimise subjective and judgmental comments in medical records and to make clear when their assessments were speculative. He also urged 'vigorous reappraisal of the extent to which information about a patient needs to be circulated' to members of other disciplines, for instance, in child health practice. If doctors did not take such steps themselves legal changes might well be imposed upon them, giving patients the right of access to their medical records and perhaps making breach of medical confidentiality a criminal offence.

$\mathrm{Mr} \mathcal{F}$ acob, a lawyer, commenting on the papers by $\mathrm{Dr}$ Pheby and MrKenny, a health administrator, argued that increased legal intervention in medical ethics could quite possibly actually erode traditional medical ethical standards of confidentiality based on peer review and 'the ethic of virtue'.

In his commentary on my recent paper on confidentiality, particularly in relation to child health (I), Dr Green provides a number of interesting illustrations of the ways in which considerations of confidentiality may enter into clinical medicine and of ways in which such considerations may be ignored or overlooked in day-to-day practice (2). I am grateful to $\mathrm{Mr}$ Jacob (3) for updating my article by reference to the recent Law Commission Report on Breach of Confidence (4), and also for underlining the lack of legal remedies available for mistakes arising from the incorporation into medical records of value judgments. However, I must take issue with him over one fundamental assertion, for I do not think I wrote anything which could be construed as indicating that I was advocating 'reliance on codes of conduct less powerful than medical ethics or a machinery less effective than that applied in the UK' (5), and neither was I suggesting that 'since much of modern medicine was based on a . . . therapeutic team, older

Key words

Confidentiality; medical ethics; medical records; doctor-patient relationship; patients' rights. understandings of the basis of medical confidences may have to be modified' (6). I was in fact making exactly the opposite point and suggesting that presene conditions require a strengthening, not a weakening of the medical ethic. Certainly, the machinery of peefo review advocated by Jacob as a means of enforcing standards of confidentiality would not appear consis tent with the principles of natural justice, in that such procedure would be neither demonstrably impartia nor necessarily afford a hearing to complainants. If any case, peer review as a means of maintaining stan dards is still in its infancy and its usefulness has still to be fully evaluated. Also, it is difficult to see how $\vec{D}$ process of peer review could be initiated by patiogitus when they are so frequently kept in ignorance of has been committed to record about them.

I concentrated in my article on the problems of confidentiality which may arise with regard to the carf of children. I suggested that two factors had combine to create difficulties: the growth of both information technology, and of a multidisciplinary approach tg child health. It is interesting that $\mathrm{Mr}$ Jacob, an academic lawyer, should take up the cudgels, for could also have cited legal changes in recent years as further factor which has contributed to the problem Doctors working with social workers and exchanging information with them, for example at case confere ences, should be aware that social workers wield veris considerable legal powers in respect of families Maidment (7) lists no fewer than I I different ways ig which local authority social services departments can take children into care, all of them enacted in legislas tion since 1969 . Confidential information transferre by doctors to third parties such as social workers ceases to be subject to medical control, and judgmental datan or even factually inaccurate information from medical records, may be quoted in evidence, for example in care proceedings to which parents are not party and is which they are not legally aidable. If legal sanctions caf be the end-result of multidisciplinary teamwork, thep there must be legal safeguards at every stage to protect the innocent against the consequences of such a poten tially damaging flow of confidential information. Pee review, though it undoubtedly has a role in maintain ing overall professional standards, in no way amounis to an adequate safeguard for the individual. 
As I have suggested, the legal position regarding medical records is very complex, and Kenny (8) performed a useful service in separating the concepts of ownership and confidentiality. It is possible to identify at least five rights subsisting in medical records, ie copyright, ownership, custody, access, and control of the use to which information is put. Copyright is largely irrelevant to the question of protecting the interests of the subject of a document, while ownership of medical records, as I have pointed out, is highly problematic. Custody, at least of hospital and community health records, rests in the National Health Service with health authorities, and Kenny has explored the way in which this right can be exploited so as to afford maximum protection of confidentiality. However, a potential problem arises, as Black and Subotsky (9) pointed out, in that multidisplinary teams in child psychiatry may transcend the bounds of the health institution and include 'non-health' employees. At this point, custodianship may break down as a safeguard for confidentiality. Control of the use to which information is put ultimately rests with the patient, or his or her legal guardian, and this will be even more the case if the Law Commission's proposals on confidentiality are enacted. The problem is how to enable patients to exert this right when information is transferred to other parties in secrecy. The solution to this must involve consideration of access to records. The choice, as I see it, lies between restricting the relatively free flow of information which takes place between professionals at the moment, and allowing patients access to their records so that they can monitor what is being transferred. In child health this would mean, in effect, taking the parents into partnership with the professionals as fellow-members of the multidisciplinary team, so that they too could contribute their unique knowledge and experience of their child, the better to fulfil his or her best interests.

\section{References}

(I) Pheby D F H. Changing practice on confidentiality: a cause for concern. Fournal of medical ethics I982; 8: I2-I8.

(2) Green M. Commentary 2: confidentially speaking. Fournal of medical ethics, 1982; 8: 2 I-24.

(3) Jacob J M. Commentary I: confidentiality: the dangers of anything weaker than the medical ethic. Fournal of medical ethics 1982; 8: 18-21.

(4) Law Commission. Report on breach of confidence. Cmnd 8388. London: HMSO, 1981 .

(5) See reference (3): 20

(6) See reference (3): 18.

(7) Maidment S. The fragmentation of parental rights and children in care. Fournal of social welfare law $198 \mathrm{I} ; 3$ : 2I-35.

(8) Kenny D J. Confidentiality - the confusion continues. Fournal of medical ethics 1982; 8: 9-I I.

(9) Black D, Subotsky F. Medical ethics and child psychiatry. Fournal of medical ethics I982; 8: 5-8. 